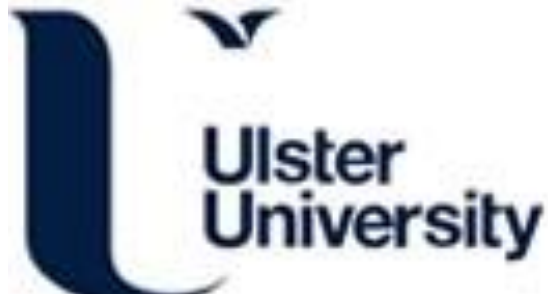

\section{An evaluation of the current mentorship/preceptorship practices for newly qualified radiographers in Northern Ireland}

Morris, K., \& Cathcart, J. (2021). An evaluation of the current mentorship/preceptorship practices for newly qualified radiographers in Northern Ireland. Radiography, 27(2), 589-597.

https://doi.org/10.1016/j.radi.2020.11.025

Link to publication record in Ulster University Research Portal

\section{Published in:}

Radiography

Publication Status:

Published (in print/issue): 01/05/2021

DOI:

10.1016/j.radi.2020.11.025

\section{Document Version}

Author Accepted version

\section{General rights}

Copyright for the publications made accessible via Ulster University's Research Portal is retained by the author(s) and / or other copyright owners and it is a condition of accessing these publications that users recognise and abide by the legal requirements associated with these rights.

\section{Take down policy}

The Research Portal is Ulster University's institutional repository that provides access to Ulster's research outputs. Every effort has been made to ensure that content in the Research Portal does not infringe any person's rights, or applicable UK laws. If you discover content in the Research Portal that you believe breaches copyright or violates any law, please contact pure-support@ulster.ac.uk. 


\section{Title:}

\section{'An Evaluation of the current Mentorship/Preceptorship practices for Newly Qualified Radiographers in Northern Ireland'}

\section{Keywords * 5:}

- Mentorship

- Preceptorship

- Competency

- Radiographer

- Induction

\section{Classifications / Highlights:}

- The perceived barriers of successful mentorship/preceptorship programmes were recognised by both participant groups

- Participants welcomed the opportunity to suggest improvements on the strategies currently performed

- Variations in mentorship/preceptorship programme delivery is a missed opportunity for Radiology Managers and NHS Northern Ireland (NI) generally to capitalise on a more cost effective, time efficient programme for consistency of staff and patient care regionally

- Recommendations for streamlining the current process already exist in the tried and tested form of the 'Flying Start $N H S \Theta^{\circ}$ ', Knowledge and Skills Framework (KSF) and Quality Service Improvement (QSI).

Declaration of interest: None.

This study did not receive any specific grant from funding agencies in the public, commercial, or not-for-profit sectors. The author reports no declarations of interest. 


\section{Title:}

\section{'An Evaluation of the current Mentorship/Preceptorship practices for Newly Qualified Radiographers in Northern Ireland'}

\section{Authors:}

Kellie Morris (PG Dip)

Dr J.M. Cathcart (D Med Sc, MSc, PG Dip, Pg CHEP, DCR $®$, FHEA)

Corresponding Author: Kellie Morris

E-mail: kellie.morris@westerntrust.hscni.net

Address: 3 Pinefield Brae, Omagh, Co.Tyrone. BT79 7YG

Author: Dr. J. M. Cathcart

E-mail: j.cathcart@ulster.ac.uk

Address: C/O School of Health Sciences, Ulster University, Shore Rd, Newtonabbey, Co. Antrim. BT38 0QB

Declaration of interest: None.

This study did not receive any specific grant from funding agencies in the public, commercial, or not-for-profit sectors. The author reports no declarations of interest. 
Title: An evaluation of the current Mentorship / Preceptorship practices for newly qualified Radiographers in Northern Ireland.

\section{Abstract}

Introduction: Mentorship/Preceptorship (M/P) has been utilised within the nursing profession since the early 1980's. Successful, structured M/P programmes can be hugely beneficial to Northern Ireland $(\mathrm{NI})$ Trusts who recruit regularly and often rely on the fluidity of staff movement regionally. In the absence of standardised tools to accurately and universally measure the competency of newly qualified Radiographers (NQR) as they evolve, establishing the benchmark for effective practice within Radiology departments in NI is difficult and highly subjective at best. This study aimed to evaluate the current M/P strategies within $\mathrm{NI}$ as perceived by NQR and Radiology Managers (RM).

Methods: A mix of both qualitative and quantitative data was obtained using questionnaires through a scoping exercise. Opinions were sought from a target audience of NQR, who began full-time employment following graduation in 2018, and $\mathrm{RM}$ involved in the delivery of current M/P programmes within the NI Trusts.

Results: Responses were gained from all five NI trusts to achieve a representative regional sample, with final opinions of $\mathrm{RM}(n=8,54 \%)$ and NQR $(n=30,67 \%)$ received. With the exception of one response, all NQRs confirmed receiving some form of $\mathrm{M} / \mathrm{P}$ support within their inaugural post.

Conclusion: Significant variations were apparent in both the structure and delivery of Trust $\mathrm{M} / \mathrm{P}$ induction programmes, calling into question the comparable competency of NQRs regionally.

Implications for practice: The disparity in approach towards $\mathrm{M} / \mathrm{P}$ programmes across $\mathrm{NI}$, and subsequent lack of comparability of NQR competence, endorses the development of a more robust and universal method for the regional assessment of NQRs, such as that of the 'Flying Start NHS®' programme utilised by National Health Service (NHS) Scotland, in combination with knowledge and skills framework (KSF) practices in supervision.

\section{Abstract Word Count: (280words)}

\section{Keywords * 5:}

- Mentorship

- Preceptorship

- Competency

- Radiographer

- Induction

Abbreviations: M/P: Mentorship/Preceptorship, NQR: Newly Qualified Radiographer, RM: Radiology Manager, M/M: Mentor/Mentee 
$1 \quad$ Title:

'An Evaluation of the current

Mentorship/Preceptorship practices for Newly

Qualified Radiographers in Northern Ireland' 
Title: An evaluation of the current Mentorship / Preceptorship practices for newly qualified Radiographers in Northern Ireland.

\author{
Keywords * 5: \\ - Mentorship \\ - Preceptorship \\ - Competency \\ - Radiographer \\ - Induction
}

\title{
Abstract
}

Introduction: Mentorship/Preceptorship (M/P) has been utilised within the nursing profession since the early 1980's. Successful, structured M/P programmes can be hugely beneficial to Northern Ireland (NI) Trusts who recruit regularly and often rely on the fluidity of staff movement regionally. In the absence of standardised tools to accurately and universally measure the competency of newly qualified Radiographers (NQR) as they evolve, establishing the benchmark for effective practice within Radiology departments in $\mathrm{NI}$ is difficult and highly subjective at best. This study aimed to evaluate the current M/P strategies within $\mathrm{NI}$ as perceived by NQR and Radiology Managers (RM).

Methods: A mix of both qualitative and quantitative data was obtained using questionnaires through a scoping exercise. Opinions were sought from a target audience of NQR, who began full-time employment following graduation in 2018, and $\mathrm{RM}$ involved in the delivery of current M/P programmes within the NI Trusts. 
Results: Responses were gained from all five NI trusts to achieve a representative regional sample, with final opinions of $\mathrm{RM}(n=8,54 \%)$ and NQR $(n=30,67 \%)$ received. With the exception of one response, all NQRs confirmed receiving some form of M/P support within their inaugural post.

Conclusion: Significant variations were apparent in both the structure and delivery of Trust $\mathrm{M} / \mathrm{P}$ induction programmes, calling into question the comparable competency of NQRs regionally.

Implications for practice: The disparity in approach towards $M / P$ programmes across $\mathrm{NI}$, and subsequent lack of comparability of NQR competence, endorses the development of a more robust and universal method for the regional assessment of NQRs, such as that of the 'Flying Start NHS®' programme utilised by National Health Service (NHS) Scotland, in combination with knowledge and skills framework (KSF) practices in supervision.

\section{Abstract Word Count: (280words)}

Abbreviations: M/P: Mentorship/Preceptorship, NQR: Newly Qualified Radiographer, RM: Radiology Manager, M/M: Mentor/Mentee 


\section{Introduction}

With the continual recruitment of NQR by NI Health Service Trusts, ${ }^{1}$ service delivery remains paramount and the timing of recruitment, whilst in some part determined by staff retention, can be variable and not totally pre-determined by managers. Under the 'Transforming Your Care' initiative, patients/service users should receive a consistent level of high quality care during any encounter within the NHS. ${ }^{2}$ In order to facilitate this, radiology departments aim to have their new recruits performing to a safe and productive level in a cost-effective timeframe..$^{3-5}$

\section{Mentorship/Preceptorship Rationale}

To enable this transition, the role of a mentor/preceptor has been identified in a variety of professions, most notably nursing, ${ }^{6}$ to facilitate continued support and induction of new staff members into their inaugural role. ${ }^{6}$ The timing of summer recruitment has implications on the department, as annual leave subscriptions are usually at their peak. An efficient and seamless introduction for the NQR, into their new post, requires thorough preparation supported by a robust induction process.

The concept of M/P is not novel, with the Society and College of Radiographers (SCoR; formally College of Radiographers, CoR) referring to the term 'preceptorship' in a 'Clinical Supervision Framework' document detailing recommended structures for a preceptorship period. ${ }^{7}$ It stipulates working regularly with a preceptor for an indeterminate period, focusing on the achievement of mutually agreed goals, with decision making and knowledge of key department protocols and processes at the forefront. A radiotherapy-based article by Nisbet $^{8}$ therefore, reinforces the sentiments of SCoR and associates the term 'preceptorship' to the concept behind 
developing a formal, structured approach to supporting the NQR as they enter the workforce. $^{8}$

In 2009, within the SCoR publication 'Mentoring: Guidance and advice', mentoring was detailed to be a dynamic process with long-term benefits to those who actively participated. At the point of NQR induction, mentoring assumes a hierarchical style where the NQR receives guidance and support from an experienced staff member in order to successfully develop their skills following transition into the department. ${ }^{9}$ The Society of Radiographers (SOR) recognises a Radiographer at the point of registration as competent to work autonomously 'at the initial level' with foundation skills requiring consolidation for continuous development. ${ }^{10}$ Whilst this is acknowledged, it is non-prescriptive in detailing key areas where an NQR should receive additional support in order to become more confident, and by a measurable outcome, competent.

The nursing field has been pro-active in both the implementation and evolution of M/P. Existing literature addresses their multi-faceted approach, reflecting on the experience from the 'preceptor/preceptee' perspective, ${ }^{11-13}$ the models used, $, 11,14$ methods of preceptor assignment, ${ }^{4,5,8}$ achieved competencies ${ }^{15,16}$ and the challenges faced in the programmes successful delivery. ${ }^{17-19}$

\section{Mentorship/Preceptorship in Radiography}

The Health and Care Professionals Council's (HCPC) 'philosophy of preceptorship' promotes the use of reflection following a novel or challenging encounter to consolidate knowledge. ${ }^{20}$ The overarching goal of a preceptorship period is to 
develop a more confident and independent practitioner, with good clinical practice, able to engage in clinical supervision throughout their career. ${ }^{21}$

\section{Key deficiencies}

Few articles published within the last decade offer guidance on the strategies practised to-date within Radiography. With on-going concerns regarding the lack of structure, Irwin et al. ${ }^{15}$ recommended making preceptorship a mandatory, structured and formalised initiative to increase confidence and competence amongst participants. ${ }^{15}$ Other authors cited the importance of establishing clear objectives to achieve aspired measurable outcomes. ${ }^{18}$ A successful M/P programme would require the co-ordinated efforts and support of the Trust, key staff and a receptive recruit to ensure its effective delivery. ${ }^{22,23}$

Whilst the Radiography profession may learn from the variety of structures practised and reviewed within nursing, authors have highlighted that the current evaluation of competency is ultimately based upon subjective observation, failing to confidently detail an appropriate and robust strategy that may be transferable interprofessionally. Therefore, the primary aim of this study is to identify the current practice of $\mathrm{M} / \mathrm{P}$ strategies within NI Radiology departments and establish congruence and opinion on its effectiveness.

\section{Methodology}

\section{Sample Characteristics}

A total of 60 participants were initially sought, consisting of $15(n=15)$ RMs and 45 $(n=45)$ NQRs from across the five main Trusts. Of these, eight RMs ( $n=8 ; 54 \%)$ and 
30 NQRs $(n=30 ; 67 \%)$ were successfully recruited and returned completed questionnaires. It was apparent in some Trusts that a RM may be responsible for more than one site. Therefore, given the duality of working roles within Trust management; the recruitment of eight RMs was considered a representative sample. All NQRs recruited had BSc Hons Degree classifications of 2:2 or higher and were employed in full-time permanent posts between July 2018 and July 2019. This timeline aligns with the course structure of graduations, regional recruitment and potential travel of participants. Permission for the study to distribute evaluative questionnaires within Radiology departments to potential participants was granted from Ulster University Ethics Committee and subsequently, NI Trusts.

\section{Procedure}

A mix of qualitative and quantitative questionnaire styles were used for data collection. Questionnaires were anonymous to protect confidentiality and prevent perceived bias and satisfying research integrity. The qualitative data was sourced using an amended form of validated NHS career development survey ${ }^{24}$ and involved seeking opinions of participants as they detailed their experiences of M/P programmes outlined (RM) or received (NQR). Questionnaire responses were then grouped into identified trends and themes using desktop analysis within the research team.

A scoping exercise was used to identify gaps between literature and the practises and mechanisms of $M / P$, with regards to meaningful mentorship experiences, and additionally obtain the opinion of those who received and delivered the programme. 


\section{Pilot Study}

A pilot study was performed to test the face validity of both amended questionnaire types prior to the proposed service evaluation, using Radiography staff deemed ineligible for the main study. The managerial questionnaires were piloted on three senior staff members (Band 7), whilst NQR questionnaires were piloted on graduates (2017) who had been employed for two years and historically mentored. Following results analysis, no potential for error in interpretation or compromised response accuracy was recorded.

\section{Questionnaire distribution and return}

Questionnaires were distributed to participants via an identified department facilitator. Recruitment of participants was via distribution of electronic recruitment packs (NQR and RM), ensuring complete anonymity. Where a suitable facilitator could not be identified, recruitment packs were posted to a named senior staff member within the department.

Responses for some questions were detailed using the 5-Point 'Likert Scale"25 ranging from "Strongly agree" to "Strongly Disagree." For ease of analysis, these have been streamlined into three categories of opinion: either "Positive", "Negative" or "Neutral" responses. ${ }^{25}$ Responses to open ended questions were analysed using thematic desktop analysis, with common themes identified and grouped together. 


\section{Results}

Responses from RM Q.1 and NQR Q.4\&5 revealed that $100 \%$ of RM offered, and subsequently $100 \%$ of NQR availed, of Trust and department induction. However, responses in the first and second columns of Figure 1 below illustrates that, in spite of initial agreement, disparity arose with regards to the timing of its completion, with some NQRs disputing that this induction happened within the first four months of their initial employment. On seeking responses, the RM and NQR may have been from the same department, in that the NQR was managed by the RM, but the opinions of both entities were grouped collaboratively to create a generic RM and NQR opinion with no site association attributed.

Figure 1: Question topics and response congruence from NQR and RM

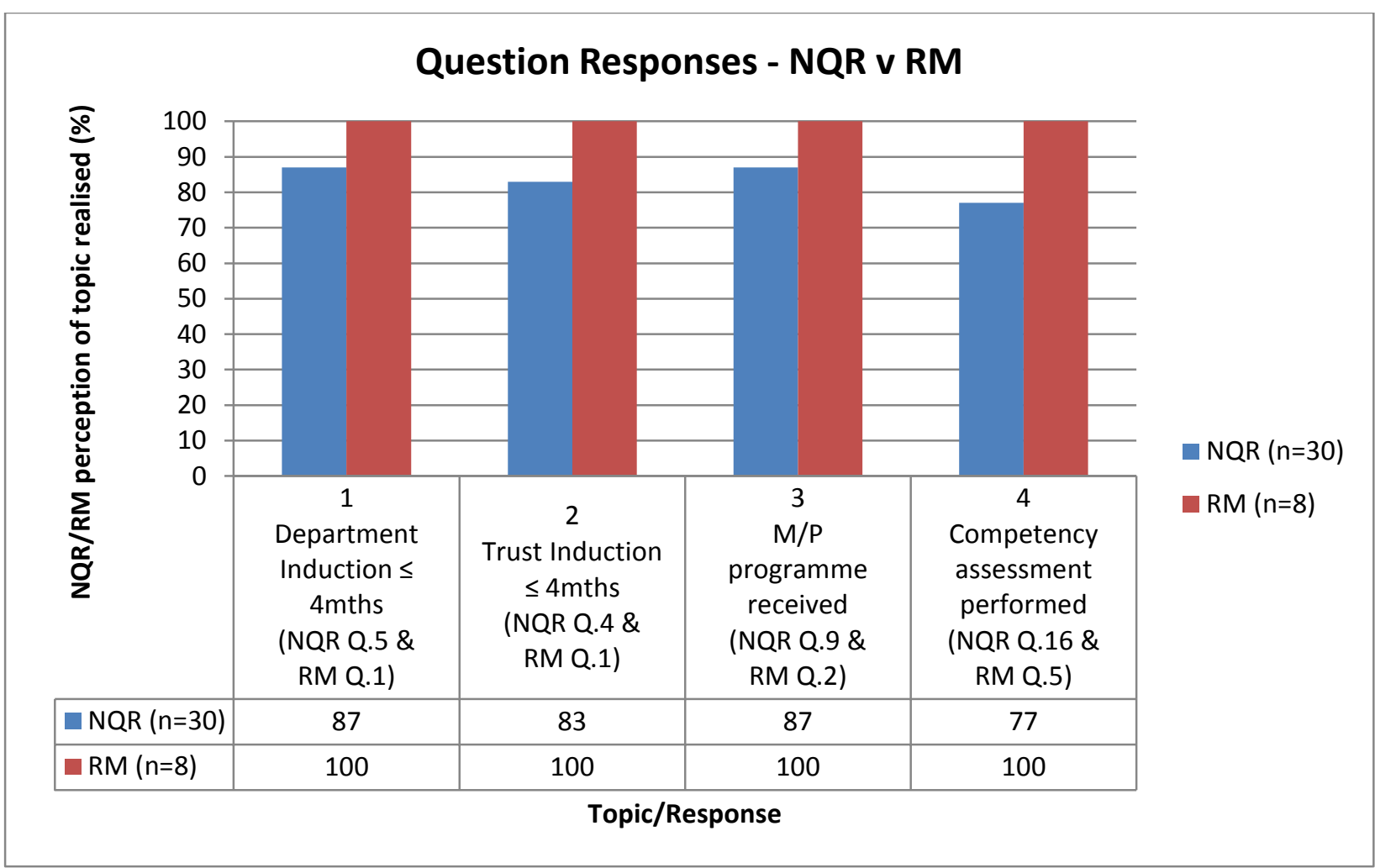

$100 \%$ of RMs confirmed provision of M/P programmes (Fig.1: column 3), despite disagreement from $13 \%$ of NQRs. Similar discrepancy is noted with regards to 
competency assessment (Fig.1: column 4), with $23 \%$ of NQR disputing being evaluated or knowingly so. If $13 \%$ of $\mathrm{NQR}$ are refuting the existence of $\mathrm{M} / \mathrm{P}$ programmes, or if the programme is available but the NQR is not aware, then this raises important questions about the structure and formality of the $M / P$ being performed. Whilst both RM/NQR may indeed be correct in their perception of the existence of the programme, what remains important is the measurable competency of staff and their fitness to practice within their role. Clearly more needs to be done to ensure that all NQRs are aware of mentorship provision in order to acknowledge their areas of proficiency and/or improvement. Furthermore, how can RMs in the same instance be confident of NQR competency, if the NQRs themselves are unaware of their own performance level or perceived expectations?

Interestingly, out of the four NQR who cited no receipt of an M/P programme (Q.9), two responded to having an identified mentor in Q.8, suggesting continued confusion with regards to having a nominated staff member for guidance (Fig.2)

\section{Figure 2: NQR responses to questions regarding M/P}

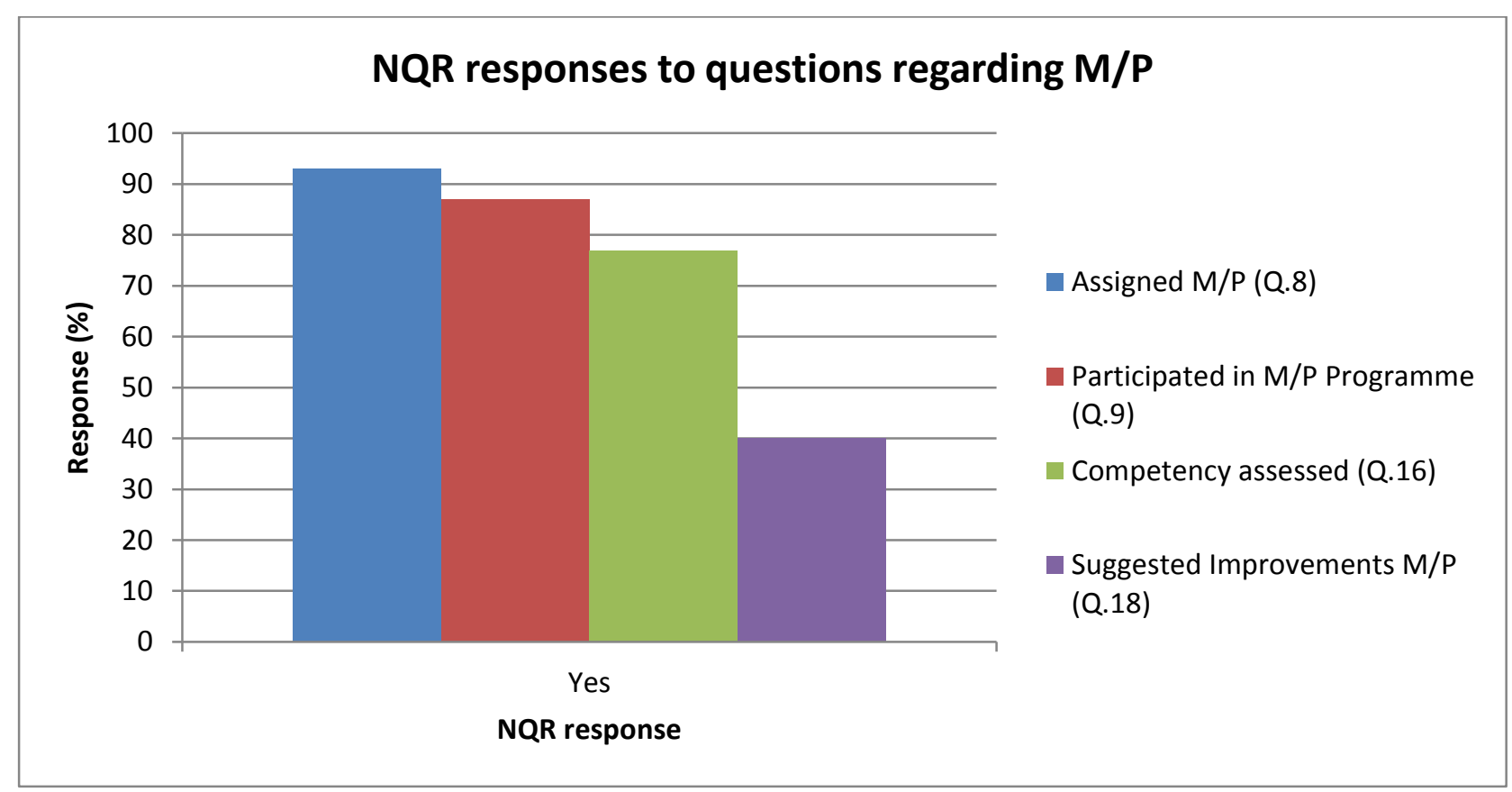


This confusion further compounds earlier concerns regarding the lack of formality

and structure of the M/P programmes. To gain insight, assessment structure and strategies were further analysed, with RM (Q.5) and NQR (Q.16) questioned on their understanding of how NQR competencies were currently evaluated. Their responses were illustrated for comparative analysis (Fig.3).

Figure 3: Competency assessment strategies utilised by RM and comparative NQR understanding

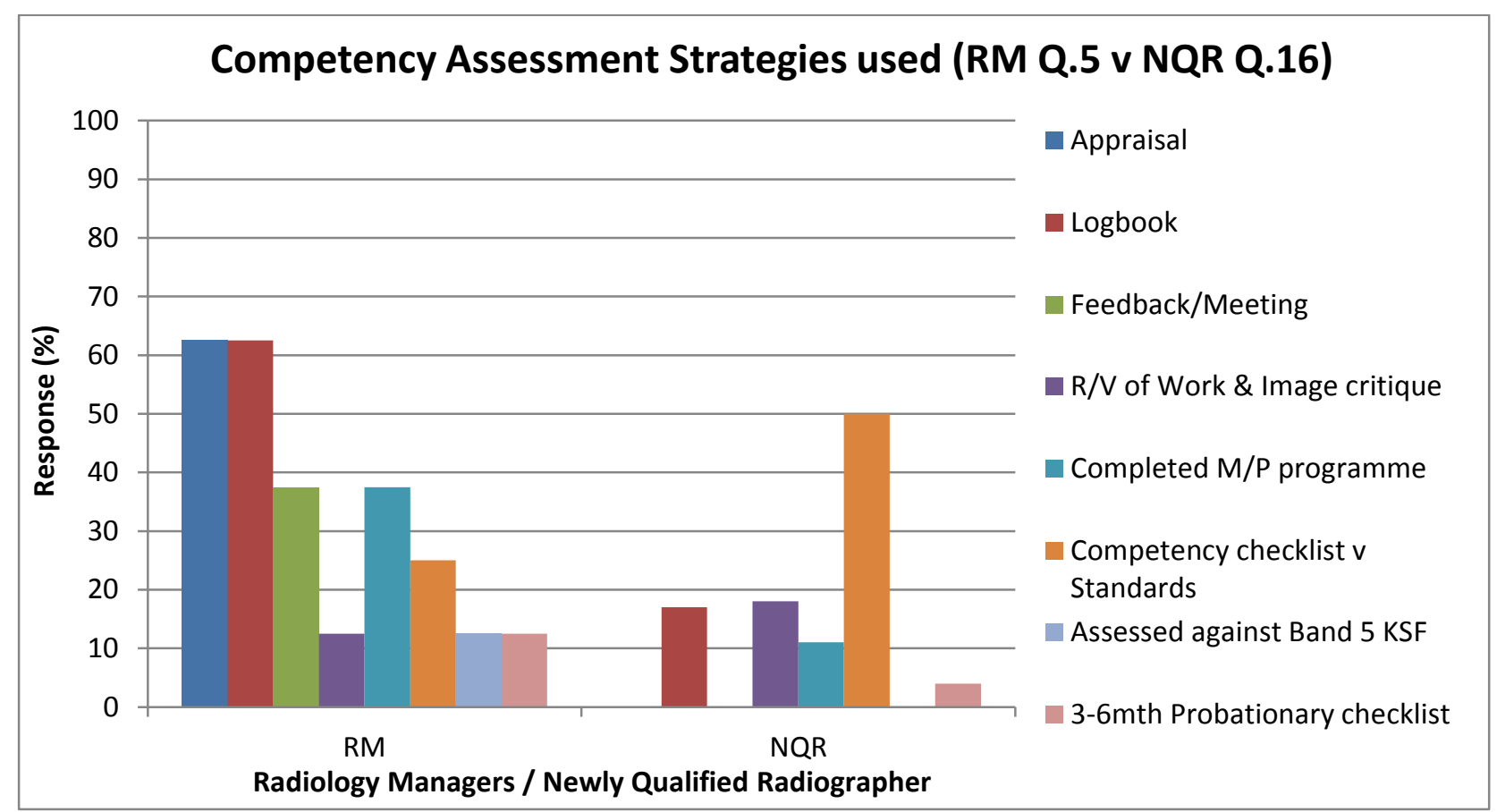

Figure 3 above, highlights the huge variability of NQR competency assessment strategies used and the disagreement between RM/NQR of what is being received. The raw data revealed only two RMs are unified in their approach to competency assessment (Appraisal, logbook and Feedback/meeting). The most popular form of assessment (cited by RMs) appears to be either 'Appraisal' or 'Logbook', with $50 \%$ of RM using a combined approach and only one RM providing NQRs with a review of their work and image critique. Strikingly not a single NQR detailed having an 
appraisal conducted as part of their competency assessment. Indeed, in Figure 1, only $77 \%$ of NQR detailed receiving any form of recorded assessment, suggesting a possible lack of awareness of their participation in the process.

Remarkably, Band 5 KSF standards were used by only one RM. Arguably the most structured and objective means of assessment available within the last two decades, Band 5 KSF provides a hierarchy of core dimensions to be achieved.$^{26}$ Therefore, it appears to be surprisingly underutilised.

\section{Mentor Selection}

RM cited mentor selection as being pre-assigned, based on preferable attributes (Fig.4). All eight RMs reported including 'experience' in their appointment decision and detailed it distinct to a staff's awarded 'Band'. Other Trusts chose to utilise their Band 7 reporting Radiographers as mentors, given their ability to offer additional guided image critique. Further analysis revealed that only $25 \%$ of mentors had attended a mentorship course Trust-wide.

\section{Figure 4: Rationale for mentor selection by RM}

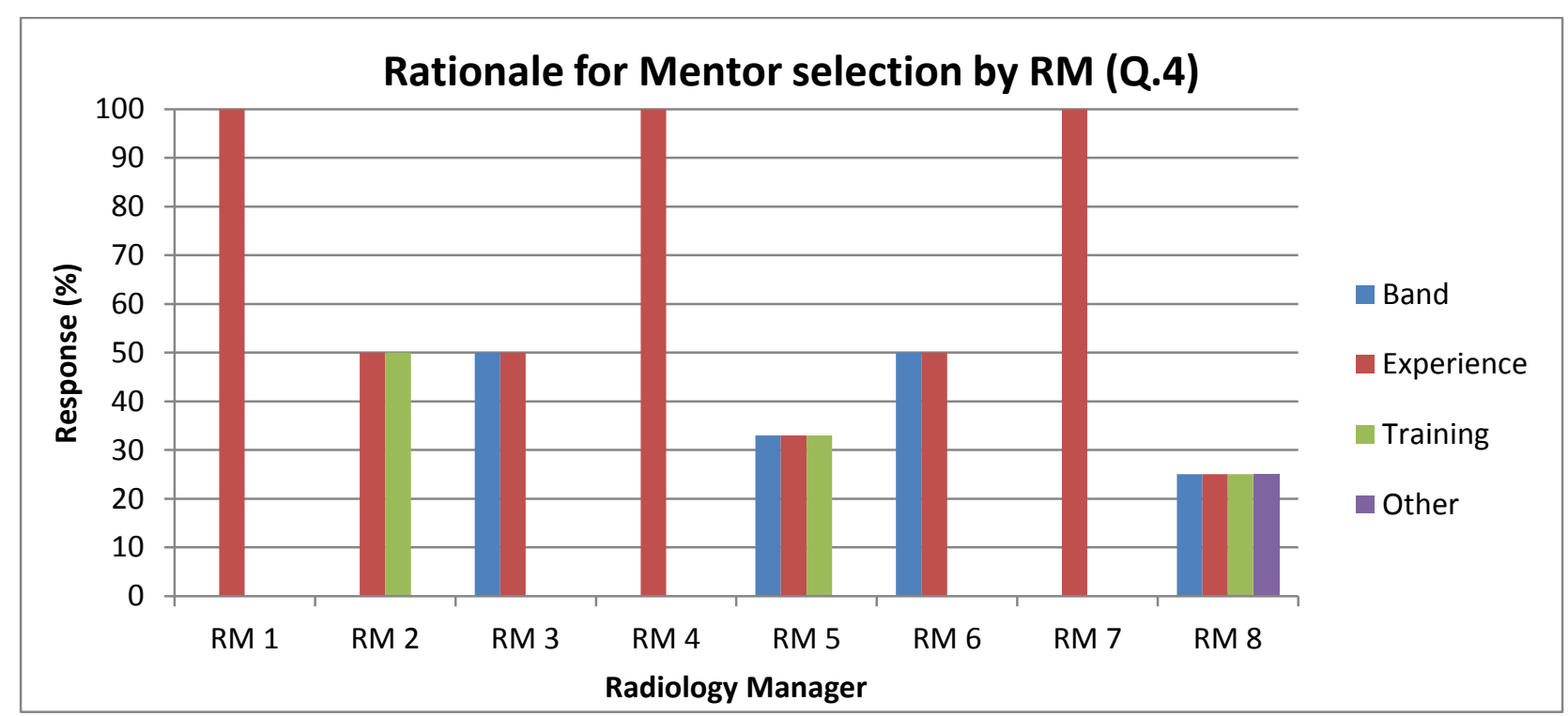




\section{Duration of $M / P$ Programme}

Across all Trusts, variations in the duration of $\mathrm{M} / \mathrm{P}$ programmes were evident, ranging from a minimum of $0-8$ weeks, to periods greater than 48 weeks (Fig.5). This further highlights the need for consistency across the board when it comes to the structure, use and success of an M/P programme. Without a universal approach to the assessment of NQRs regionally, it leads to the inevitable variability in the structure and subsequent duration of an M/P programme.

\section{Figure 5: The duration of M/P programmes provided by RMs}

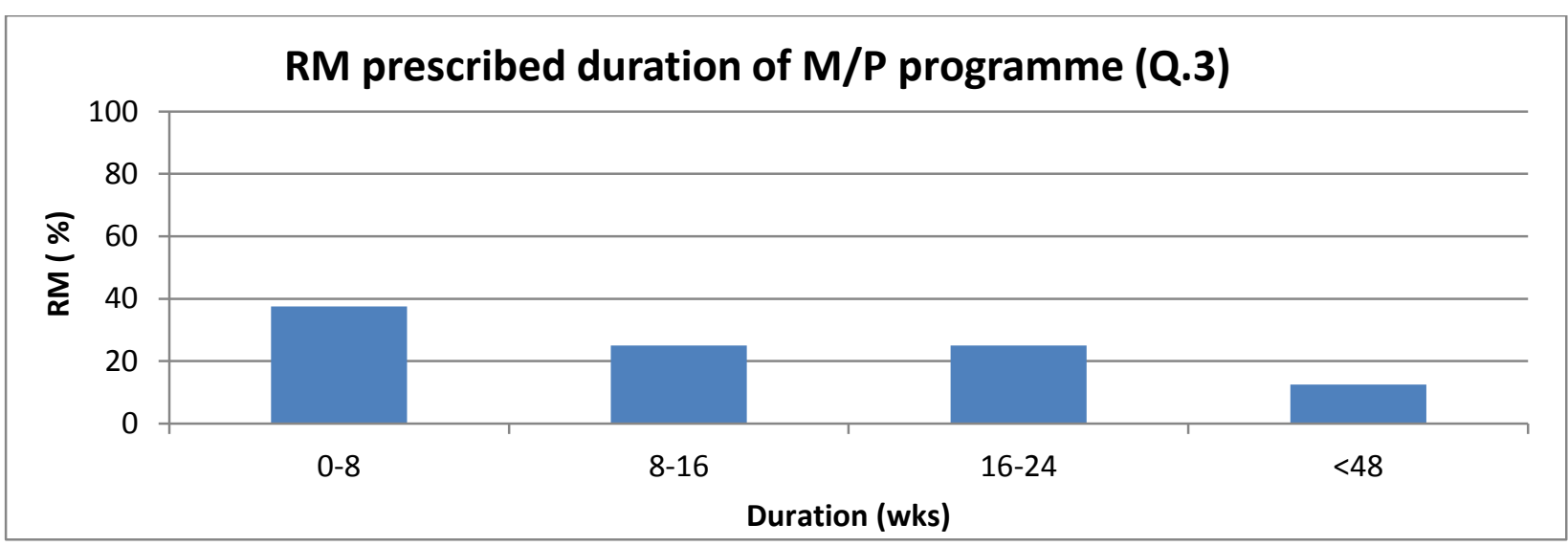

\section{Barriers to Delivery}

Overwhelmingly, the main barriers identified by RM (Fig.6) were 'Time' and 'Availability of a mentor'; closely followed by 'Staffing Levels'. The relationship between these is cyclical; reductions in staffing levels leads to increased demand placed on remaining staff, with mentors being reassigned to alternate tasks at the expense of the programme. The identification of these barriers may coincide with the earlier variance in $\mathrm{M} / \mathrm{P}$ programme duration; as the repeated presence of such prevents its completion in a timely manner. 
One RM states:

- "..the general timing of NQR starts is when $A / L$ is highest so dept is skeletally staffed". ${ }^{\mathrm{M} 1}$

- Another said: "... sick leave can deplete the volume of available staff to provide the aspired programme". ${ }^{\mathrm{M} 5}$

These sentiments are shared by some NQRs:

- "Mentorship process rushed due to staff shortages", ${ }^{\text {NQR25 }}$

- "not getting adequate time with mentor. Not easy for either mentor/mentee". NQR30

Figure 6: The perceived barriers to successful M/P delivery by RMs

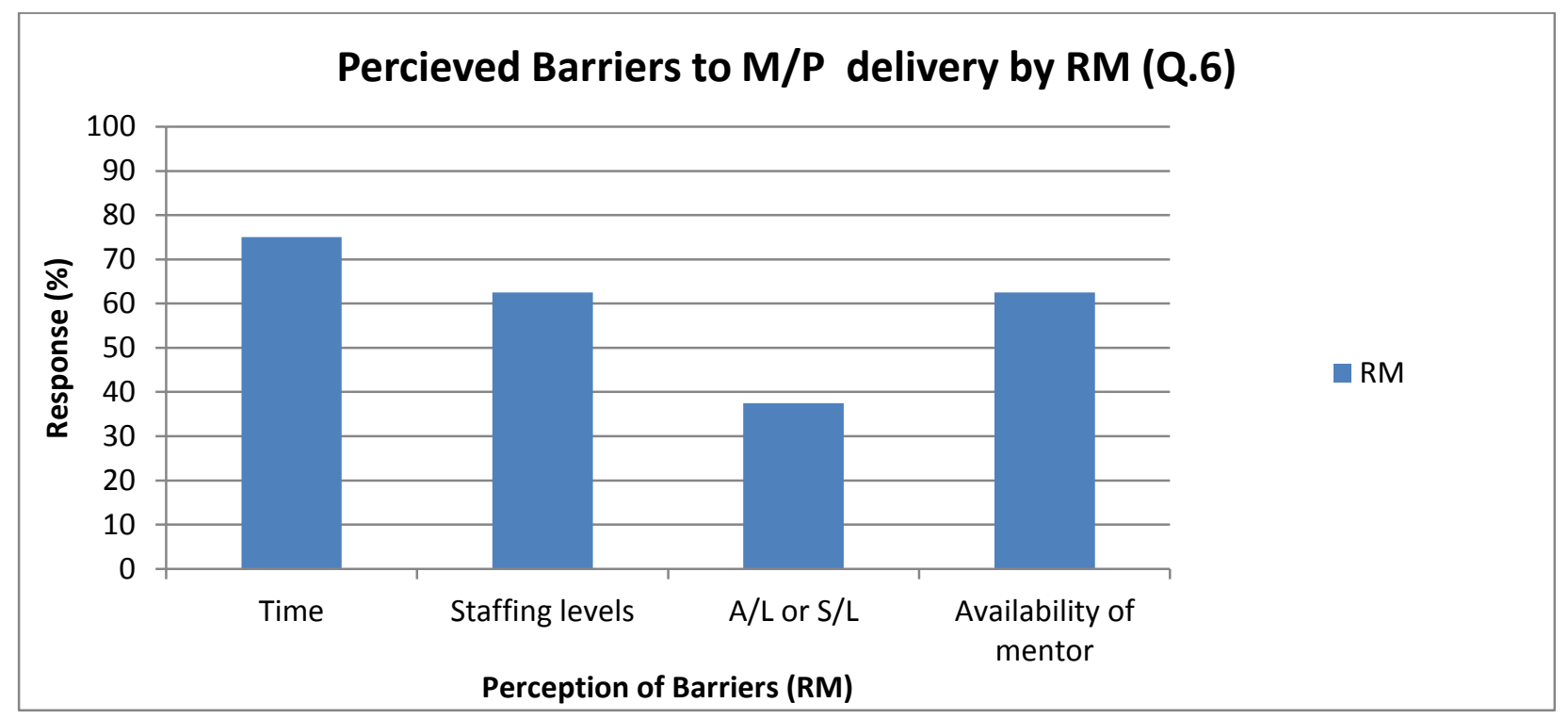

In spite of the above barriers, $70 \%$ of NQRs reported having meetings with their mentor at least once a month, with $36 \%$ once or more per week (Fig.7). Given the inconsistency of competency assessment strategies (Fig.3), the fact that only $77 \%$ of NQRs detailed having a recorded assessment (Fig.1), combined with the apparent confusion of NQRs over receipt of M/P programmes, it is difficult to know if the meetings were formally recorded or were simply informal "check-in" meetings. 
Furthermore, whilst a particular staff member may have been given the title of 'mentor', other staff could have been offering support to the NQR on a daily basis, thus adopting an ad-hoc form of mentorship. To avoid confusion, it is recommended that meetings should be scheduled according to the realisation of learning outcomes and recorded with full participation from both parties.

Figure 7: Frequency of reported meetings during M/P period by NQRs

\section{Frequency of meetings with mentor/preceptor (Q.12)}

Daily $\square$ Few times weekly $\square$ Once a week $\square$ Few times monthly $\square$ Once a month $\square<$ once a month

\section{Overall Opinion}

The overall opinion of the value of $\mathrm{M} / \mathrm{P}$ programmes in contributing to their development was overwhelmingly positive in $87 \%$ of NQR responses, with $67 \%$ stating that it 'Met Expectations' and 20\% stating that it 'Exceeded Expectations' (Figure 8).
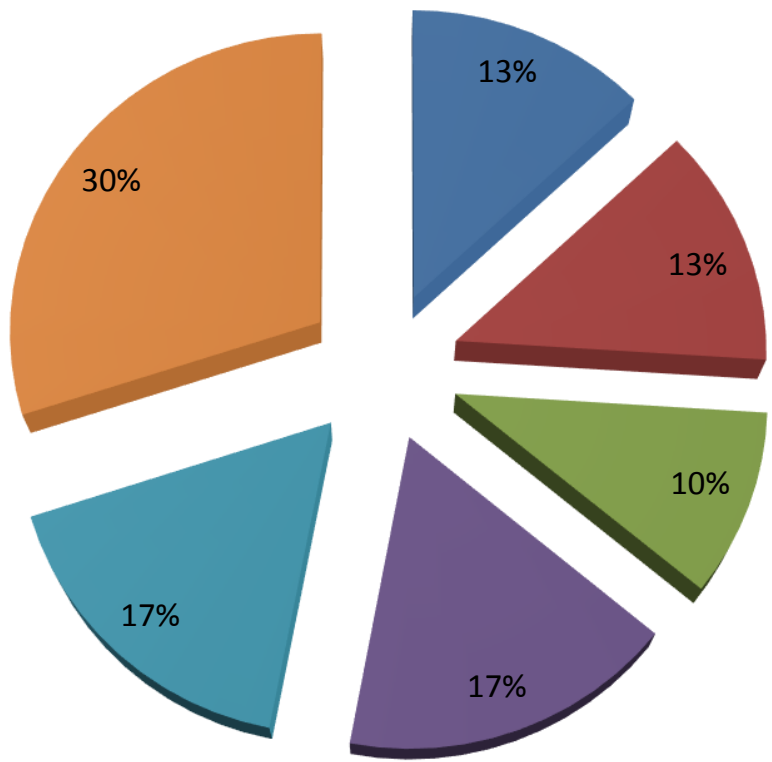

$10 \%$

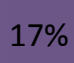


Figure 8: NQR response to the value of M/P programmes

\section{NQR Response to the value of Mentorship/preceptorship}

(Q.13)

Exceeded expectations $\square$ Met expectations Below Expectations

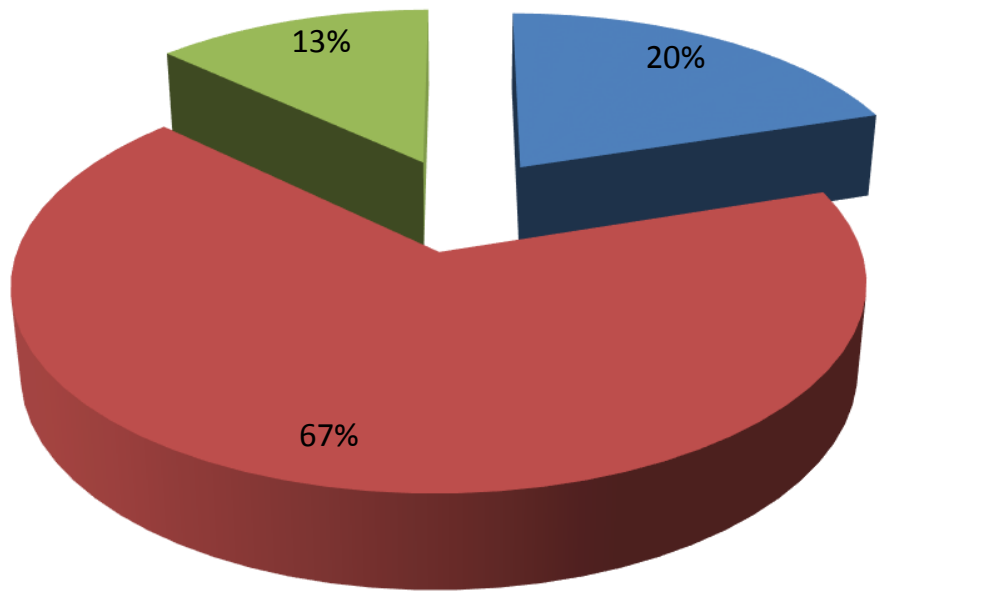

It should be noted however, that this positive response related to whether the NQR felt that they were sufficiently equipped and ready for 'lone working/on-call' by the end of the M/P period. It remains, therefore, whether (i) confusion surrounding the $\mathrm{M} / \mathrm{P}$ programme generally by NQRs (ii) its inconsistency of structure, content and assessment, and (iii) the associated barriers of delivery, have led to an overall misunderstanding of 'confidence' verses 'competence'. 


\section{Discussion}

The current study found an inconsistent approach and lack of structure to the M/P programmes regionally. Coupled with the hugely diverse system of NQR competency assessment across $\mathrm{NI}$, it is almost impossible to accurately compare approaches in their effectiveness to enhance competency. An evaluation of the most successful strategy for increasing NQR competency would be superfluous, as there is no current standard or measurement for comparison; nor does there appear to be an objective benchmark to begin with. It additionally lacks a quantitative approach to establishing current competence scores, apart from those determined through the rare use of Band 5 KSFs. Indeed, current measures of 'competence' appear to be confused or interlinked with 'confidence'; specifically, whether NQRs are deemed able and willing to work independently or complete 'on-call' shifts. This belief was further compounded by quotes from NQRs: "after discussing the checklist with my mentor I felt prepared and ready to start on-call' ${ }^{\text {NQR28 }}$ and "Whilst anxious, I had completed adequate training to enable lone-working". "NQR29 What transpired from the results of this study is that there is a necessary and timely need for an accurate, universal strategy for NQR competence assessment. .

It is completely understandable, given years of NHS underfunding, growing patient waiting times and increased staff workload, that 'Time', 'Staffing Levels' and 'Availability of a mentor' were cited as the three most prominent barriers to the successful delivery of an M/P programme. In an idealistic recruitment process, an RM would aspire for a 'proactive not reactive' approach; however in reality, much of the drive for recruitment is fuelled by sudden staff diminishment such as with the recent unprecedented demand on NHS services following the Coronavirus 
pandemic. The need for increased staffing to allow "protected time" between mentor and mentee $(\mathrm{M} / \mathrm{M})$ seems an obvious remedy, but given the above-mentioned concerns with regards to lack of funding and sudden, exceptional surges in staff demand, this may not be possible. Barriers to sustained programme delivery reflect the reality of competing responsibilities in a work environment under unrelenting demands. Colthart et al. $^{3}$ recommended protected time as a pre-requisite to any successful mentoring process to ensure that mentor duties were consistently fulfilled in addition to existing workloads. ${ }^{3}$ More recently, Bingmar et al. ${ }^{27}$ and furthermore McDaniel et al. ${ }^{28}$ evidenced the need to avail of electronic connections in attempts to mitigate such barriers. ${ }^{27,28}$

\section{The 'Flying Start $\mathrm{NHS} \AA^{\circledR}$ ' programme}

One possible solution to this seemingly perpetual issue would be to employ the use of an electronic or online learning and development system. The SCoR document 'Mentoring: Guidance and Advice'9 lists some of the possibilities for mentorship delivery. ${ }^{9}$ Providing NQRs with a means to improve their education/skillset outside of work time would provide a 24-7 access point for remote learning, whilst simultaneously eradicating the burden of securing additional protected time in an already busy Radiology department. Additionally, remote mentoring could be utilised for off-site mentors who may not be accessible to the mentee, whilst still enabling them to avail of support. Erol et al. ${ }^{4}$ reviewed the use of online blended methods that deliver a mentor-led programme supported by a web based system. ${ }^{4}$ One such initiative already successfully utilised in Scotland is known as the 'Flying Start $N H S \AA^{\prime}$, which aids in the transitioning process for nursing and Allied Health Professionals in their first year of clinical practice..$^{29}$ In use since 2006, The Flying 
Start ensures that "all of its NHS activities are mapped to the NHS KSF Core Dimensions," ${ }^{, 26}$ meaning that it could be easily married with existing Radiology KSF markers, supporting recommendations made by Jackson ${ }^{16}{ }_{.16}^{16,26}$ Given the comparable regional size and dynamic of $\mathrm{NI}$, the 'Flying Start NHS®' initiative could seamlessly bridge the current gap in addressing the needs of consistent M/P delivery for Radiographers. Whilst Erol et al. ${ }^{4}$ acknowledged the benefits of the programme, it also highlighted some limitations similar to the findings of this study; (i) time/mentor availability and (ii) endorsement of the organisation in the concept. Theoretically, the programme would offer the NQR an online learning framework combined with the provision of additional support by an allocated department mentor. The programme is purpose-designed to build confidence and competence in measurable and consistent ways, as the NQR would embrace a self-directed style of learning: identifying their own areas of additional development and building on their undergraduate knowledge. This may then provide the structure that NQRs repeatedly referred to as 'lacking' in their responses throughout this study, whilst simultaneously fostering accountability in their own development. Furthermore, spare time could be more efficiently utilised for subsequent scheduled mentor meetings.

For the mentor, the 'Flying Start $N H S \Theta$ ' programme offers wider accessibility to resources, allowing for a more streamlined mentor training programme, increasing the effectiveness of their mentorship, and offering a more consistent approach across NHS NI.

For the RM, this programme delivers an already tried and tested form of support for all newly qualified employees in line with staff governance standards; combining existing links with the current KSF assessment programme. Additionally, RMs are 
comparatively consistent not just locally, but regionally and potentially nationally; with opportunities to benefit from shared learning and training resources offered in other areas (for example Scotland). Regional consistency would capitalise on the fluidity of staff movement across Trusts, with RMs confident that staff coming from any Trust within $\mathrm{NI}$ have been trained to an equivalent standard. Finally, and perhaps most importantly, it would provide links with Government standards, supporting and promoting safe and effective practice, in line with recommendations by Nowell et al. ${ }^{14}$

\section{Quality Service Improvement}

Complementing the 'Flying Start $N H S \circledast$ ' could be the use of Quality Imaging Standards (QIS) and an electronic quality management system (QMS) such as 'QPulse'. Both specifically relate to facilities, workforce and resources, enabling reviews of proficiency across all Bands in department tasks and training. Q-Pulse could be designed to record the frequency by which a task is performed within a role: determining if staff are/remain skilled and ultimately competent. Combining an online blended mentorship programme with a purpose-built section of QMS would encourage staff ownership in recording all aspects related to their training and Continuous Professional Development (CPD).

Furthermore, this would support the idea of a team-mentoring approach suggested by Farah et al. ${ }^{30}$, in ensuring the NQR receives the appropriate level of training from staff suitably skilled in that area. ${ }^{30}$ Q-Pulse can ensure that work instructions, training records or reference documents are to hand for the NQR to review and/or complete, whilst the RM can audit whether or not staff have viewed the documents or participated in training, with records held to coincide. 


\section{Mentorship Choice and Training}

The study found that all departments had a pre-assigned mentor selection process performed by RM based on desired qualities (Fig.4); a process that may or may not allow the chosen member of staff to decline. Whilst the majority of relevant literature acknowledges that any formal mentoring attempt is positive in aiding transition to clinical practice, Kostrubiak et al. ${ }^{22}$ detailed the disadvantages of a 'forced' mentorship experience, as it ignores the need for 'chemistry' in its success. ${ }^{22}$ In a similar context, Holliday et al. ${ }^{31}$ referred to 'fruitful mentoring relationships' and 'formal programs for pairing the $M / M$ '; whilst Bingmer et al. ${ }^{27}$ detailed a 'matching process' in ensuring desired 'chemistry' between $\mathrm{M} / \mathrm{M}$, with others detailing the positive influences of successful preceptee/preceptor relationships further to selfselection. ${ }^{11,27,31,32}$ Whilst important to consider the impact of pre-assignment strategies on $M / M$ morale, this study found no reference to conflict within $M / M$ relationship highlighted by NQRs.

An area not directly addressed in this study but highlighted in other articles was that of the mentor opinion on programme successes and burden of the role. Quek and Shorey ${ }^{12}$ and Valizedah et al. ${ }^{18}$ felt that the additional workload delegated to a mentor was unrealistic and unachievable. ${ }^{12,18}$ Inadvertently, this study may have highlighted such difficulties through the lack of training mentors receive and the prevalence of NQR comments regarding time constraints and the need for "protected time". The relationship between poor mentor training and inconsistent mentorship success is well evidenced, with recommendations for adequate investment in mentors to ensure their awareness of educational processes are supported by clinical based academic staff to remain knowledgeable..$^{12,18}$ 
With the 'Flying Start NHS®' programme offering the mentor wider accessibility to resources and the possibility of a more co-ordinated mentor training programme, the aforementioned issues and "burden" could be alleviated, with the mentor able to redirect the NQR to online supplementary learning in their absence and increase the effectiveness of their mentorship overall.

\section{Limitations}

It should be acknowledged that this study was not without limitations.

A larger sample size inclusive of mentor opinion could offer a more rounded view of current M/P practises within NI. Whilst the study was successful in maximising its sample within $\mathrm{NI}$, future related studies could compare opinion of other M/P programmes nationally. Moreover, including the opinion of the mentor in future studies could highlight potential discrepancies between what an RM 'believes' is happening and what is 'realised in the busy department and potentially serve to mitigate any affirmation bias.

The study did not establish if a positive $\mathrm{M} / \mathrm{P}$ programme had any impact on staff retention within a Trust or if the same investment was made in staff employed on a temporary contract.

Furthermore, the study did not obtain the opinions of the NQR nor the mentor themselves on the process of 'mentor selection', which could have provided additional insight for further exploration.

\section{Conclusion:}

This study sought to evaluate the current M/P practices for NQR in $\mathrm{NI}$ and found that, with best intentions, the current method of practice, content, structure and 
delivery of an M/P programme for NQR is simply too diverse. The result of these variations is a missed opportunity for RMs and NHS NI generally to capitalise on a more cost effective, time efficient programme for consistency of staff and patient care regionally. Recommendations for streamlining the current process already exist in the tried and tested form of the 'Flying Start $N H S{ }^{\circledR}$ ', KSF and QSI; it is just a matter of putting the wheels in motion to get $\mathrm{NHS} \mathrm{NI}$ to invest in its use and application.

In acknowledging the aforementioned limitations identified by Erol et al., ${ }^{4}$ similar to the findings of this study; (i) time/mentor availability and (ii) endorsement of the organisation in the concept, heightened awareness of these pitfalls would prevent overlooking these essential pre-requisites from the outset and lend to its success. A development considered mandatory, with clear assessment criteria and a common understanding of completion should ensure that both NQR and management fully support the programme capable of evolving its work force.

It is acknowledged that individual Trusts and departments may have specialised techniques and equipment that requires further knowledge, training and skills development. This may be local only to that clinical environment, prior to the NQR being deemed competent. However, this could coexist as a supplementary component to an already existing universal programme such as the 'Flying Start NHS $\AA^{\prime}$.

The fact that RMs across the Trusts are committed to delivering and providing some form of M/P programme for their NQRs, in spite of ever increasing barriers, is very positive. Ultimately, it remains that Trusts and departments need to fully invest in a rigorous and uniform $\mathrm{M} / \mathrm{P}$ process as an asset, to ensure that all recruits acquire the embedded skillset necessary for the delivery of optimum quality patient care. 
Unfortunately, unless Trusts move to a more robust, accurate and universally comparable assessment system for NQRs such as that of the established 'Flying Start $N H S \Theta / B$ and $5 \mathrm{KSF}$, then despite the best efforts of RMs, the delivery of consistent quality care will be a varied process across $\mathrm{NI}$.

\section{Article Word count: 3994words}

\section{Conflict of interest statement}

None

\section{Declaration of interest disclosure statement}

This study did not receive any specific grant from funding agencies in the public, commercial, or not-for-profit sectors. The author reports no declarations of interest. 


\section{References}

1. The Society and College of Radiographers SCoR. Diagnostic Radiography Workforce UK Census 2018. Available at: https://www.sor.org/sites/default/files/documentversions/diagnostic workforce census 2018.pdf

[Accessed 10/10/2019]

2. Department of Health. Transforming Your Care: A Review of Health and Social Care in Northern Ireland 2011. Information Office C5.20 Castle Buildings Stormont Belfast Northern Ireland BT4 3SQ: department of health. Available at: http://www.transformingyourcare.hscni.net/wpcontent/uploads/2012/10/Transforming-Your-Care-Review-of-HSC-inNI.pdf [Accessed 20/11/2018].

3. Colthart, I., McBride, M. and Murray, M. Mentoring assistant practitioners-The radiographer's perspective. Radiography 2010;16(3):223-229. Doi:10.1016/j.radi.2010.03.004

4. Erol, R., Upton, P. and Upton, D. Supporting completion of an online continuing professional development programme for newly qualified practitioners: A qualitative evaluation. Nurse Education Today 2016;42: 62-68. http://dx.doi.org/10.1016/j.nedt.2016.04.005

5. Nielson, K., Finderup, J., Brahe, L., Elgaard, R., Elsborg, A. M., EngellSoerensen, V., Holm, L. and Juul, H. The art of preceptorship. A qualitative study. Nurse Education in Practice 2017;26:39-45. http://dx.doi.org/10.1016/j.nepr.2017.06.009

6. Chickerella, B.G. and Lutz, W.L. Professional nurturance: Preceptorships for undergraduate nursing students. American Journal of Nursing 1981; 81(1):107-109

7. The College of Radiographers (COR). Clinical Supervision Framework 2003. The College of Radiographers, 207 Providence Square, Mill Street, London. SE1 2EW: Sue Shelley. Source URL: https://www.sor.org/learning/document-library/professional-supervisionadvice-and-guidance-document

8. Nisbet, H. A model for preceptorship - The rationale for a formal, structured programme developed for newly qualified radiotherapy radiographers. Radiography 2008;14(1):52-56. doi:10.1016/j.radi.2006.07.004

9. The College of Radiographers. Mentoring: Guidance and advice 2009. London: SCor https://www.sor.org/learning/document-library/mentoringguidance-and-advice

10. The Society and College of Radiographers. Society of Radiographers publications 2018. 207 Providence Square, Mill Street, London SE1 2EW: The Society and College of Radiographers. Available at: https://www.sor.org/ [Accessed 20/11/2018].

11. Omer, T.Y., Suliman, W.A., Thomas, L. and Joseph, J. Perception of nursing students to two models of preceptorship in clinical training. Nurse Education in Practice 2013;13(3):155-160. http://dx.doi.org/10.1016/j.nepr.2013.02.003 
12. Quek, G.J. and Shorey, S. Perceptions, Experiences, and Needs of Nursing Preceptors and Their Preceptees on Preceptorship: An Integrative Review. Journal of Professional Nursing 2018;34:417-428. https://doi.org/10.1016/j.profnurs.2018.05.003

13. Raub, J.N., Fiorvento, A., Franckowiak, T.M., Wood, T. and Gortney, J.S. Implementing and sustaining a mentorship program at a college of pharmacy: The Keys to Successful Mentorship. Currents in Pharmacy Teaching and Learning 2017;9(2):296-301. http://dx.doi.org/10.1016/j.cptl.2016.11.017

14. Nowell, L., Norris, J.M., Mrklas, K. and White, D.E. A literature review of mentorship programs in academic nursing. Journal of Professional Nursing http://dx.doi.org/10.1016/j.profnurs.2017.02.007

2017;33(5):334-344.

15. Irwin, C., Bliss, J. and Poole, K. Does Preceptorship improve confidence and competence in Newly Qualified Nurses: A systematic literature review 2018;60:35-46. http://dx.doi.org/10.1016/j.nedt.2017.09.011

16. Jackson, C. Assessment of clinical competence in therapeutic radiography: a study of skills, characteristics and indicators for future career development. Radiography 2007;13(2):147-158. doi:10.1016/j.radi.2005.12.003

17. Aboshaiqah, A. and Qasim, A. Nursing interns' perception of clinical competence upon completion of preceptorship experience in Saudi Arabia. Nurse Education Today 2018;68:53-60. https://doi.org/10.1016/j.nedt.2018.05.021

18. Valizadeh, S., Borimnejad, L., Rahmani, A., Gholizadeh, L. and Shahbazi, S. Challenges of the preceptors working with new nurses: A phenomenological research study. Nurse Education Today 2016;44:9297. http://dx.doi.org/10.1016/jnedt.2016.05.021

19.Zawaduk, C., Healey-Ogden, M., Farrell, S., Lyall, C. and Taylor, M. Educator informed practice within a triadic preceptorship model. Nurse Education in Practice 2014;14(2):214-219. http://dx.doi.org/10.1016/j.nepr.2013.08.008

20. Health and Care Professions Council (HCPC). HCPC Fitness to practice. 2018. Park house, 184 Kennington Park Road, London, SE11 4BU: HCPC, Fitness to Practise Department. Available at: http://www.hpc-uk.org/registrants/ftp/ [Accessed 20/11/2018].

21. Morton-Cooper, A. and Palmer, A. Mentoring, preceptorship and clinical supervision: a guide to professional support roles in clinical practice. 2000; 2nd ed. Oxford: Blackwell Science.

22. Kostrubiak, D.E., Kwon, M., Lee, J., Flug, J.A., Hoffmann, J.C., Moshiri, M., Patlas, M.N. and Katz, D.S. Mentorship in radiology. Current Problems in Diagnostic Radiology 2017;46(5):385-390. http://dx.doi.org/10.1067/j.cpradiol.2017.02.008

23. Slanetz, P.J. and Boiselle, P.M. Mentoring matters. American Journal of Roentgenology 2012;198(1):W11-W12. DOI:10.2214/AJR.11.7227

24.NHS Staff survey Results. Available at: http://www.nhsstaffsurveyresults.com/wpcontent/uploads/2020/01/ST19-Detailed-Spreadsheets FINAL.xIsx [Accessed 20/11/2018] 
25. Likert, R. A Technique for the Measurement of Attitudes. Archives of Psychology 1932;140:1-55.

26. Department of Health. NHS knowledge and skills framework (NHS KSF) and the development review process. 2004 Available at: http://www.ksf.scot.nhs.uk/uploads/documents/KSF Handbook.pdf [Accessed 12/10/2019]

27. Bingmer, K., Wojnarski, C.M., Brady, J.T., Stein, S.L., Ho, V.P. and Steinhagen, E. A Model for a Formal Mentorship Program in Surgical Residency. Journal of Surgical Research 2019;243:64-70. https://doi.org/10.1016/j.jss.2019.04.068

28. McDaniel, C.E., Rooholamini, S.N., Desai, A.D., Reddy, S and Marshall, S.G. A Qualitative Evaluation of a Clinical Faculty Mentorship program using a realist evaluation approach. Academic Pediatrics 2020;20(1):104-112. https://doi.org/10.1016/j.acap.2019.08.008

29. NHS SCOTLAND. Flying Start NHS® Policy for Newly Qualified Nurses, Midwives and Allied Health Professionals, 2018. NHS Education for Scotland, Westport 102, West Port, Edinburgh. EH3 9DN: TURAS. Available at: https://learn.nes.nhs.scot/735/flying-start-nhs [Accessed 13/11/2018].

30. Farah, R.S., Goldfarb, N., Tomczik, J., Karels, S. and Hordinsky, M.K. Making the most of your mentorship: Viewpoints from a mentor and mentee. International Journal of Women's Dermatology 2020;6:63-67. https://doi.org/10.1016/j.jijwd.2019.12.002

31. Holliday, E.B., Jagsi, R., Thomas Jr, C.R., Wilson, L.D. and Fuller, C.D. Standing on the shoulders of giants: results from the Radiation Oncology Academic Development and Mentorship Assessment Project (ROADMAP). International Journal of Radiation Oncology ${ }^{*}$ Biology* Physics 2014;88(1):18-24. http://dx.doi.org/10.1016/j.jijobp.2013.09.035

32. Yamada, K., Slanetz, P.J. and Boiselle, P.M. Perceived benefits of a radiology resident mentoring program: comparison of residents with self-selected vs assigned mentors. Canadian Association of Radiologists Journal 2014;65(2):186-191. http://dx.doi.org/10.1016/j.carj.2013.04.001 


\section{Acknowledgements}

I would like to extend special thanks to the following: Academic advisor Dr J Cathcart and former colleague Mrs N McMorris. Thanks to those who offered support within the researchers Trust, the participants and the regional Professional Practice Educator network. 